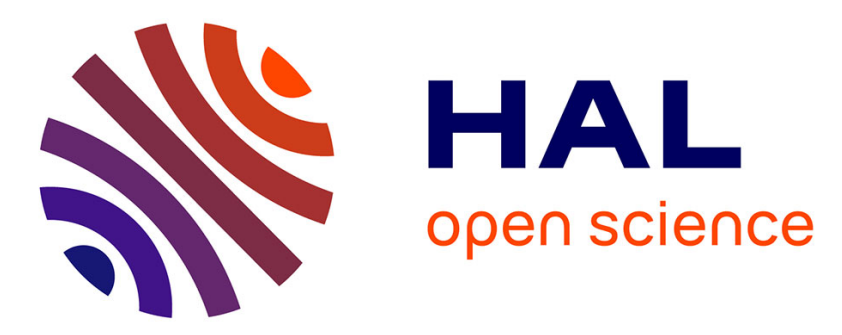

\title{
Construction of the stack insulators and acceleration tube elements used in the 5 MV Van de Graaff of Atomki
}

\author{
I. Berecz, Á. Kiss, E. Koltay, I. Papp, A. Szalay, R. Dźmuraň
}

\section{To cite this version:}

I. Berecz, Á. Kiss, E. Koltay, I. Papp, A. Szalay, et al.. Construction of the stack insulators and acceleration tube elements used in the 5 MV Van de Graaff of Atomki. Revue de Physique Appliquée, 1977, 12 (10), pp.1511-1516. 10.1051/rphysap:0197700120100151100 . jpa-00244358

\section{HAL Id: jpa-00244358 https://hal.science/jpa-00244358}

Submitted on 1 Jan 1977

HAL is a multi-disciplinary open access archive for the deposit and dissemination of scientific research documents, whether they are published or not. The documents may come from teaching and research institutions in France or abroad, or from public or private research centers.
L'archive ouverte pluridisciplinaire HAL, est destinée au dépôt et à la diffusion de documents scientifiques de niveau recherche, publiés ou non, émanant des établissements d'enseignement et de recherche français ou étrangers, des laboratoires publics ou privés. 


\title{
CONSTRUCTION OF THE STACK INSULATORS AND ACCELERATION TUBE ELEMENTS USED IN THE 5 MV VAN DE GRAAFF OF ATOMKI
}

\author{
I. BERECZ, Á. KISS, E. KOLTAY, I. PAPP, A. SZALAY \\ Institute of Nuclear Research of the Hungarian \\ Academy of Sciences, P.o.b. 51, 4001 Debrecen, Hungary \\ and R. DŽMURAŇ \\ Nuclear Research Institute of the Czecho-Slovakian \\ Academy of Sciences, Rez, Czecho-Slovakia
}

\begin{abstract}
Résumé. - Des essais mécaniques, optiques et électriques ont été effectués sur des pièces de colonne isolante et de tube d'accélération, pièces faites de différents verres de silicate de bore, fabriquées par la vitrerie hongroise. Le but des investigations a été la sélection des éléments de construction convenables pour un générateur Van de Graaff fait par l'Institut. Les expériences obtenues durant les premières 10 mille heures du fonctionnement du générateur sont présentées.

Abstract. - Mechanical, optical and electrical tests have been performed on stack insulators and acceleration tube elements made of different borosilicate glasses produced by the Hungarian glass industry. The aim of the investigation was to select the proper construction elements for a home-made 5 MV Van de Graaff accelerator. The experiences obtained during the first ten thousand hours of running the machine will be presented.
\end{abstract}

1. Introduction. - In a series of earlier papers [1], [2], [3], [4] some technical details of the home made 5 Million Volt Van de Graaff generator of our Institute have been treated. The aim of the present work is to present the mechanical, optical and electrical investigations performed in selecting the material of the stack insulator and acceleration tube. The measurements were performed on cemented glass-and-metal units, consequently the results obtained represent not only the physical properties of the glass used as insulating material in these elements but also those of the stack elements and acceleration tubes of the given construction. The measurements made it also possible to choose the optimum construction from the point of view of the cementing technology.

Sample have been used made of Hungarian borosilicate glasses called as pyrover and C-9. As the electrical breakdown tests performed on acceleration tube elements indicated lower electrical resistivity and poor electro-erosion properties in the case of Pyrover further investigations were limited to the glass C-9. Using this material satisfactory test data were obtained serving as basis for a reliable work of the generator to be built up.

The normal polyvinyl acetate technology has been followed in cementing the metallic electrodes to the glass insulating rings both in the cases of the stack and the acceleration tube. The inner electrode plates of the acceleration tubes can be fixed to the electrode supporting annuli after the sealing is completed. This construction made it possible to use the same tube with different electrode configurations [5].

The insulators have been operating about ten thousands hours in the machine with good results.

2. Cementing technology. - Polyvinyl acetate has been used as an adhesive in cementing the stack and tube test samples and actual construction elements of the generator. A solution of $20 \mathrm{~g} \mathrm{P.V.A.} \mathrm{in} 100 \mathrm{~cm}^{3}$ acetone is applied to the grounded glass surface in measured quantity in the shape of a stripe. The layer is to be dried at room temperature through 1-2 hours and to be kept at the temperature $160^{\circ} \mathrm{C}$ for 4 hours in order to get a uniformly distributed layer free of bubbles. The insulators are to be assembled in a jig which provides a pressure of $2.4 \mathrm{kp} \mathrm{cm}^{2}$ over the sealing area. The jig is then placed in an oven and baked at $170{ }^{\circ} \mathrm{C}$ for three hours. The rate of fall of temperature at the end of the bake is arranged to be $10{ }^{\circ} \mathrm{C}$ per hour to $125{ }^{\circ} \mathrm{C}$ and $4{ }^{\circ} \mathrm{C}$ per hour to $65^{\circ} \mathrm{C}[6]$.

3. Mechanical and optical tests. - The maximum tensile stress obtained from measurements on homo- 
geneous glass samples is $500 \mathrm{kp} / \mathrm{cm}^{2}(1)$. Our measurements performed on a stack sample composed of glass discs and aluminium sheets at a temperature of $22^{\circ} \mathrm{C}$ gave a value of $314 \mathrm{kp} / \mathrm{cm}^{2}$. The difference amounting to $37 \%$ of the maximum tensile stress of pure glass can be interpreted as the order of magnitude of the compressive strain left in the glass after cementing due to the different thermal expansion of metallic and glass construction parts. This value must tremendously depend on the dimension and material of the metal parts as well as on the temperature of the stack. In order to reach the best possible construction we have performed a series of optical observations on stress distributions in cemented glass-metal structures under different conditions.

As it is usual in material testing based on photoelasticity the samples have been placed between crossed polaroid foils $[7,8]$. The presence of any mechanical strain in the glass results in turning the direction of the polarization of the light, consequently the places of equal strains will appear as places of equal light intensity after the analyser foil. In order to avoid the dependence of the optical diagram on the direction of the strain circularly polarized light has been used between polarizer and analyser foils. The transformation of linear polarization into circular one at the entrance and the regain of linear polarization at the exit has been obtained by a pair of $\lambda / 4$ foils placed after the polarizer and before the analyser at angles $45^{\circ}$ and $135^{\circ}$, respectively, measured from the direction of polarization of the polarizer. A transparent sample without any strain will result in dark field of sight. With increasing strain lighthening and darkening will follow each other periodically corresponding to a phase shift of $\lambda / 4$ between neighbouring minima and maxima. Therefore in the following considerations the magnitude of the strain will be measured in units of $\lambda / 4$ by counting simply the number of light and dark lines in the vicinity of the point in question. A NaJ solution with refraction index near to that of the glass filled up the parallel walled cuvette housing the sample. In this way optical distortions on the cylindrical glass surfaces have been avoided. The temperature of the sample was changed from $35^{\circ} \mathrm{C}$ down to $-5^{\circ} \mathrm{C}$.

Typical photographs taken with this technics are shown in figures 1 and 2 . Figure 3 presents some of the results obtained from a number of such photographs. In this series of measurements samples of shape shown in the inset of figure 3 have been tested at different temperatures with aluminium and iron as electrode material. Figure 1 corresponds to the case of aluminium electrodes $3.4 \mathrm{~mm}$ thick and sample temperature $14.5^{\circ} \mathrm{C}$. The presence of strong strain is visualized by the appearing of five light and four dark stripes near the electrode corresponding to the total phase shift of $9 \lambda / 4$ near the cementing plane. The

(1) Karcag Glass Factory, (private communication).

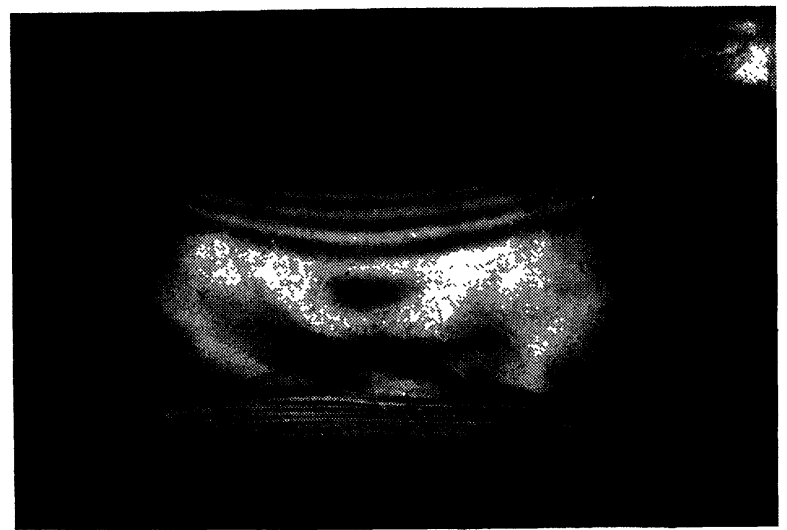

FIG. 1. - Compressive strain amounting to $90 \%$ of the maximum tensile stress in a glass disc cemented to aluminium electrodes $3.4 \mathrm{~mm}$ thick.

Temperature: $14.5^{\circ} \mathrm{C}$.

Photograph taken in polarized light.

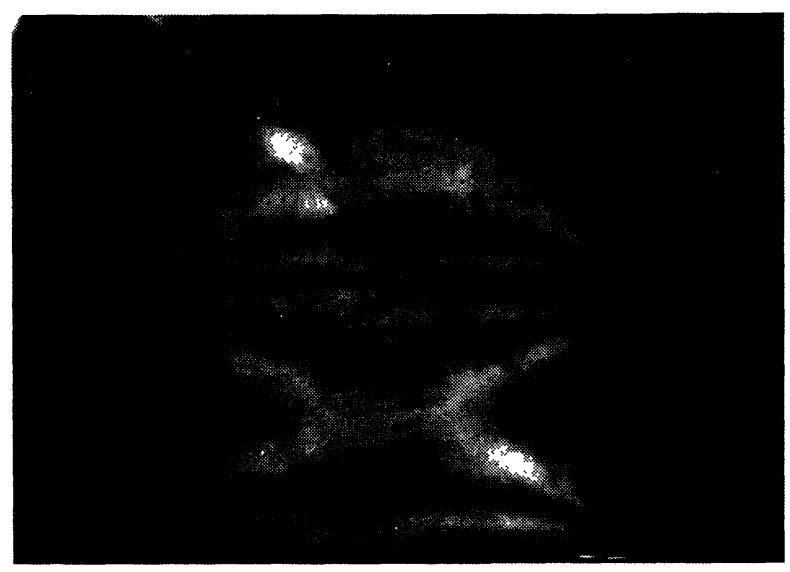

FIG. 2. - Strain in stack sample with aluminium electrode $1 \mathrm{~mm}$ thick. Temperature: $6{ }^{\circ} \mathrm{C}$.

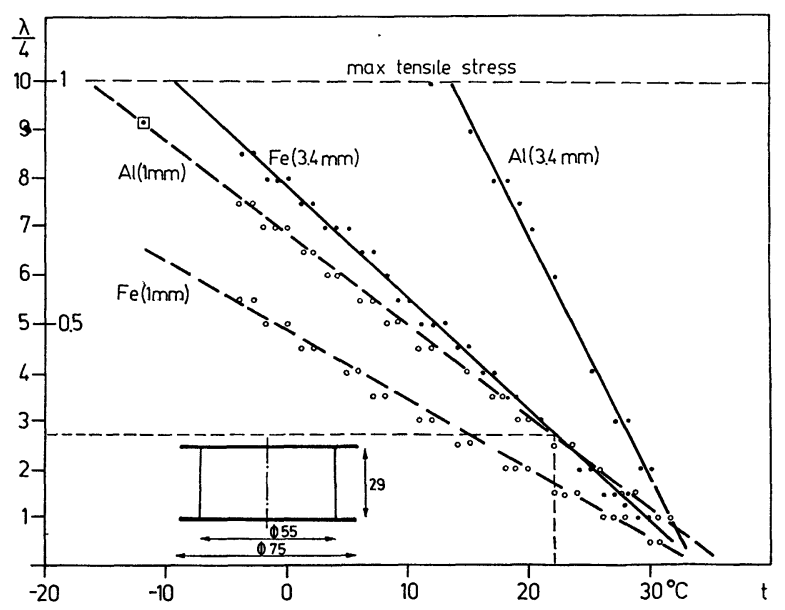

FIG. 3. - Strain expressed in units of $\lambda / 4$ and in percentages of the maximum tensile stress for the indicated glass-and-metal structures versus sample temperature.

number of the stripes increases with decreasing temperature. A breaking has always been observed in the case when the total phase shift ranged to $10 \lambda / 4$. This 
observation gave us a percental scale of measuring the strain on which maximum tensile stress corresponds to the value $10 \lambda / 4$.

The illustrative values of figure 3 show that in a good construction thin electrodes made of iron (or stainless steel) are to be used. The temperature dependence of the present curves indicates that the stack will become practically strainless at normal working temperature $30-35^{\circ} \mathrm{C}$ and the one built with stainless steel electrodes of $1 \mathrm{~mm}$ thickness will reach breaking only at the temperature $-18{ }^{\circ} \mathrm{C}$. The square at $-13{ }^{\circ} \mathrm{C}$ indicates the observation that aluminium samples remained unbroken at this low temperature. The strain at $22{ }^{\circ} \mathrm{C}$ amounts to $28 \%$ for aluminium electrodes which is near to the $37 \%$ difference between the maximum tensile stress for pure glass and for cemented glass-and-metal samples.

Figure 2 taken at $6{ }^{\circ} \mathrm{C}$ with $1 \mathrm{~mm}$ thick aluminium

TABLE I

Electrical test on $C-9$ tube insulator

\begin{tabular}{|c|c|c|c|c|c|c|c|c|}
\hline \multirow[b]{3}{*}{$\begin{array}{l}\text { Voltage } \\
\mathrm{kV}\end{array}$} & \multicolumn{3}{|c|}{ Forming } & & \multicolumn{4}{|c|}{$\begin{array}{l}\text { Characteristics measured } \\
\text { after forming }\end{array}$} \\
\hline & & Number & & & Voltage & after & $\begin{array}{r}i \text { in } \mu \mathrm{A} \\
\text { forming }\end{array}$ & in to \\
\hline & $\begin{array}{l}\text { Time } \\
\text { min. }\end{array}$ & $\begin{array}{c}\text { of } \\
\text { breakdowns }\end{array}$ & $\begin{array}{c}l_{\mathrm{star} t} \\
\mu \mathrm{A}\end{array}$ & $\begin{array}{l}l_{\text {end }} \\
\mu \mathrm{A}\end{array}$ & $\mathrm{kV}$ & $90 \mathrm{kV}$ & $120 \mathrm{kV}$ & $180 \mathrm{kV}$ \\
\hline 10 & 5 & 0 & 0 & 0 & 10 & 0 & 0 & 0 \\
\hline 20 & 5 & 0 & 0 & 0 & 20 & 0 & 0 & 0 \\
\hline 30 & 5 & 0 & 0 & 0 & 30 & 0 & 0 & 0 \\
\hline 40 & 5 & 0 & 0 & 0 & 40 & 0 & 0 & 0 \\
\hline 50 & 10 & 0 & 0 & 0 & 50 & 0 & 0 & 0 \\
\hline 60 & 10 & 0 & 0 & 0 & 60 & 0 & 0 & 0 \\
\hline 70 & 10 & 0 & 0 & 0 & 70 & 0 & 0 & 0 \\
\hline 80 & 15 & 30 & 0 & 0 & 80 & 0 & 0 & 0 \\
\hline 90 & 15 & 7 & 0 & 0 & 90 & 0 & 0 & 0 \\
\hline 0 & 5 & & & & 100 & - & 0 & 0 \\
\hline $0-90$ & 9 & 5 & 0 & 0 & 110 & - & 0 & 0 \\
\hline 100 & 30 & 66 & 0 & 0 & 120 & - & 0 & 0 \\
\hline 110 & 30 & 93 & 0 & 0 & 130 & - & - & 0 \\
\hline 120 & 30 & 110 & 0 & 0 & 140 & - & - & 0 \\
\hline $0-120$ & 13 & 1 & 0 & 0 & 150 & - & - & 0.2 \\
\hline 130 & 30 & 204 & 0 & 0 & 160 & - & - & 0.8 \\
\hline 140 & 5 & 2 & 0 & 0 & 170 & - & - & 0.5 \\
\hline 0 & 17 h 37 & & & & 180 & - & - & 0.8 \\
\hline 10 & 1 & 0 & 0 & 0 & & & & \\
\hline 20 & 1 & 0 & 0 & 0 & & & & \\
\hline 30 & 1 & 0 & 0 & 0 & & & & \\
\hline 40 & 1 & 0 & 0 & 0 & & & & \\
\hline 50 & 1 & 0 & 0 & 0 & & & & \\
\hline 60 & 1 & 0 & 0 & 0 & & & & \\
\hline 70 & 1 & 0 & 0 & 0 & & & & \\
\hline 80 & 1 & 1 & 0 & 0 & & & & \\
\hline 90 & 1 & 0 & 0 & 0 & & & & \\
\hline 100 & 5 & 10 & 0 & 0 & & & & \\
\hline 110 & 5 & 3 & 0 & 0 & & & & \\
\hline 120 & 10 & 15 & 0 & 0 & & & & \\
\hline 130 & 5 & 29 & 0 & 0 & & & & \\
\hline 140 & 30 & 119 & 0 & 0 & & & & \\
\hline $150-180$ & 34 & 142 & 0 & 0 & & & & \\
\hline $0-120$ & 12 & 0 & 0 & 0 & & & & \\
\hline 120 & 1 & 0 & 0 & 0 & & & & \\
\hline 130 & 3 & 0 & 0 & 0 & & & & \\
\hline 140 & 1 & 0 & 0 & 0 & & & & \\
\hline 150 & 1 & 4 & - & 0.2 & & & & \\
\hline 160 & 1 & 2 & - & 0.8 & & & & \\
\hline 170 & 1 & 2 & - & 0.5 & & & & \\
\hline 180 & 3 & 41 & - & 0.8 & & & & \\
\hline
\end{tabular}


electrode cemented between two glass discs illustrates that the symmetric arrangement produces only moderate mechanical strain [9]. The value of strain as low as $30 \%$ is to be compared with the corresponding value of $58 \%$ taken from figure 3 for asymmetric arrangement. That is why end flanges of the actual stack insulators and tube sections are cemented to the first glass insulators by the insertion of a ring plate made of alloy Vd-50 exhibiting a thermal expansion coefficient near to that of the glass C-9.

4. Electrical tests. - The electrical properties of Pyrover and C-9 glasses were tested in the Nuclear Research Institute of the Czecho-Slovakian Academy of Sciences where one of the authors (R.D.) had developed a testing bench for measuring insulation current, micro-discharges and breakdowns up to a voltage of $200 \mathrm{kV}$ on acceleration tube sections pumped down inside and housed in a pressurized vessel. Prior to our measurements a number of systematic investigations had been performed on different samples and a consequent way of evaluating the experimental data had been developed. The details of experimental techniques and evaluation was described in paper [10].

In the present measurements tube sections with the shape shown as case (b) in figure 4 had been tested and the results were compared with those obtained in [10] for a section made of calit with dimensions shown as case (a) in the figure.

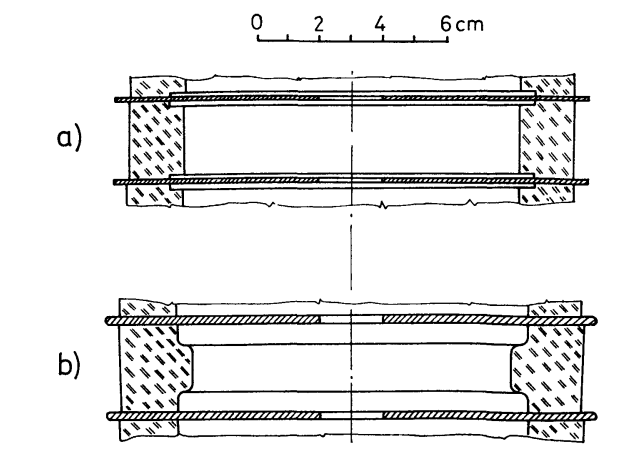

FIG. 4. - Tube sections used in electrical tests.

One series of the experimental results consisting of data measured during the conditioning procedure and of voltage-current characteristics taken in the voltage intervals below the actual conditioning voltages is shown for the case of a gap made of C-9 in table I. The data were evaluated in terms of parameters defined in Table II. The conclusions are summarized in the value of optimum voltage limit $U_{\text {opt }}$ defined as

$$
U_{\mathrm{opt}}=\left\{\begin{array}{l}
<U_{\mathrm{b} 1, \max } ; U_{\mathrm{oi}, \min }, \min \left(U_{\mathrm{dc}}, U_{\mathrm{dc}, 1}\right) \\
\leqslant U_{\mathrm{io}, \max } ; U_{\mathrm{fo}, 1} .
\end{array}\right.
$$

The C-9 turned out to be superior to Pyrover owing to the high voltage threshold for insulation current and stability against electro-erosion. No

TABLE II

Comparison of the characteristic values

INSULATOR MATERIAL

Insulator length, $\mathrm{mm}$

Conditioning time, $\mathrm{h} / \mathrm{min}$.

Max. conditioning voltage, $\mathrm{kV}$

Limitation, inside breakdown

outside breakdown

bushing breakdown

Damages, inside insulation current

First breakdown in conditioning $\mathrm{kV}$ in char. measurements, $\mathrm{kV}$

Highest conditioning voltage with $i<0.1 \mu \mathrm{A}, \mathrm{kV}$

Max. voltage with observable conditioning effect, $\mathrm{kV}$

Min. voltage without conditioning effect, $\mathrm{kV}$

Threshold for current sensitive to conditioning, $\mathrm{kV}$

Threshold for permanent current, $\mathrm{kV}$

Max. voltage with $i<0.1 \mu \mathrm{A}$ in char. measurements, $\mathrm{kV}$

Max. voltage with $i<1.0 \mu \mathrm{A}$ in char. measurements, $\mathrm{kV}$

Optimum voltage limit for the gap, $\mathrm{kV}$

$\begin{array}{lccc} & \text { CALIT [10] } & \text { PYROVER } & \text { C-9 } \\ & 25 & 28 & 28 \\ t & 11 / 14 & 3 / 0 & 5 / 8 \\ U_{\text {f, } \max } & 176 & 130 & 180 \\ & + & + & - \\ & + & + & - \\ & - & - & + \\ & + & + & - \\ & + & + & - \\ U_{\mathrm{bl}} & - & + & - \\ U_{\mathrm{bl}, \max } & 120 / 152 & 120 / 130 & 150 / 180 \\ U_{\mathrm{f} 0,1} & 86 & 110 & 140 \\ U_{\mathrm{io}, \max } & 142 & 120 & 180 \\ U_{\text {oi, } \min } & 100 & 130 & 180 \\ U_{\mathrm{dcl}} & 108 & 110 & 150 \\ U_{\mathrm{dc}} & 138 & 120 & 180 \\ U_{0,1 \max } & 104 / 124 & 110 / 130 & 150 / 180 \\ U_{1,0 \max } & 132 / 140 & 110 / 130 & 150 / 180 \\ U_{\text {opt }} & 74 & 110 & 140\end{array}$




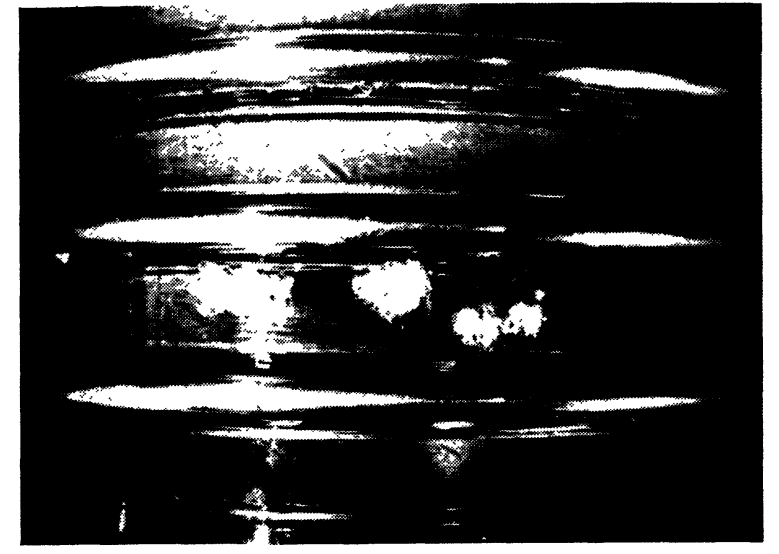

Fig. 5. - Electro-erosion spots appeared during electrical tests on the surface of Pyrover rings.

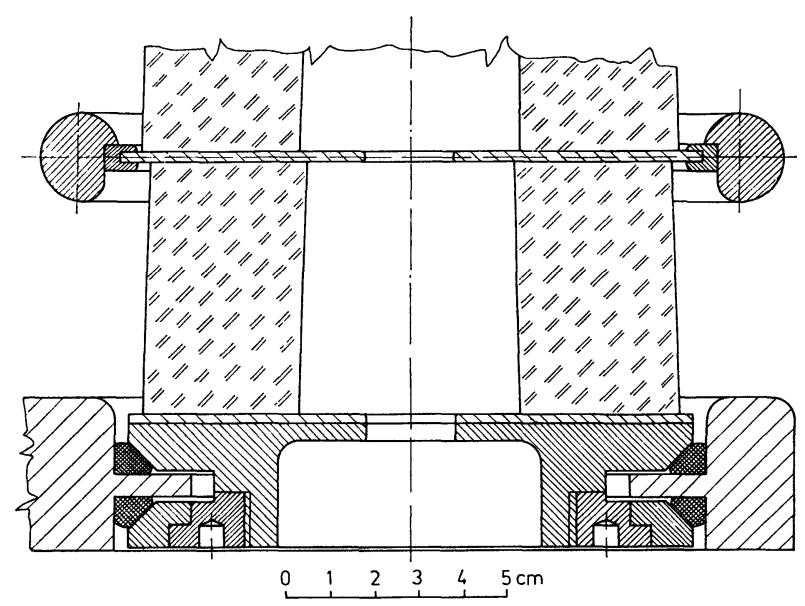

Fig. 6. - Construction of the stack insulator in the $5 \mathrm{MV}$ machine.
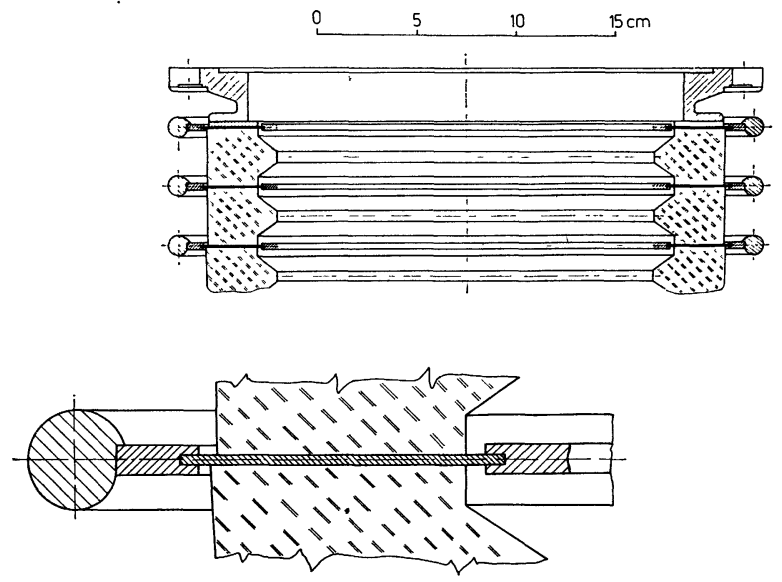

FIG. 7. - Construction of the tube insulator in the $5 \mathrm{MV}$ machine.

damages were observed after the high voltage tests in this case while quite serious damages appeared on the outer surface of Pyrover samples as shown in figure 5. The absolute numbers seem also pretty high compared with the nominal voltage difference $42 \mathrm{kV}$ on a gap of the $5 \mathrm{MV}$ accelerator.

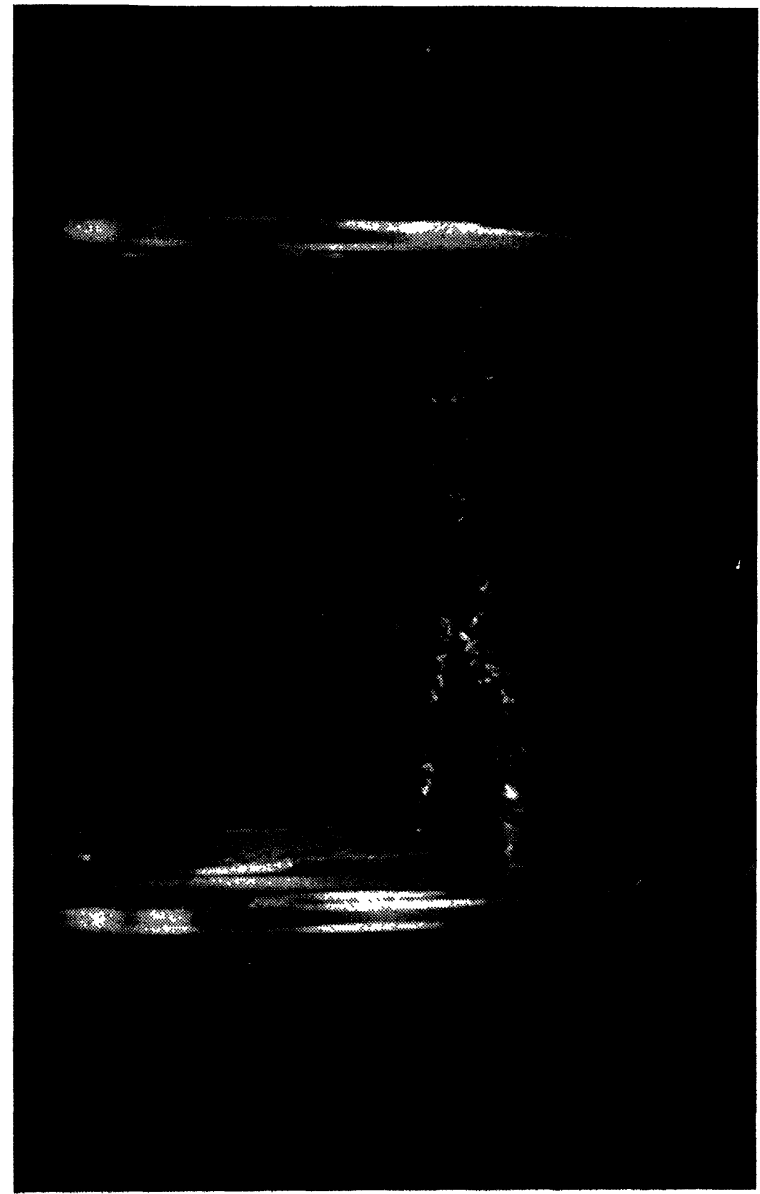

a)

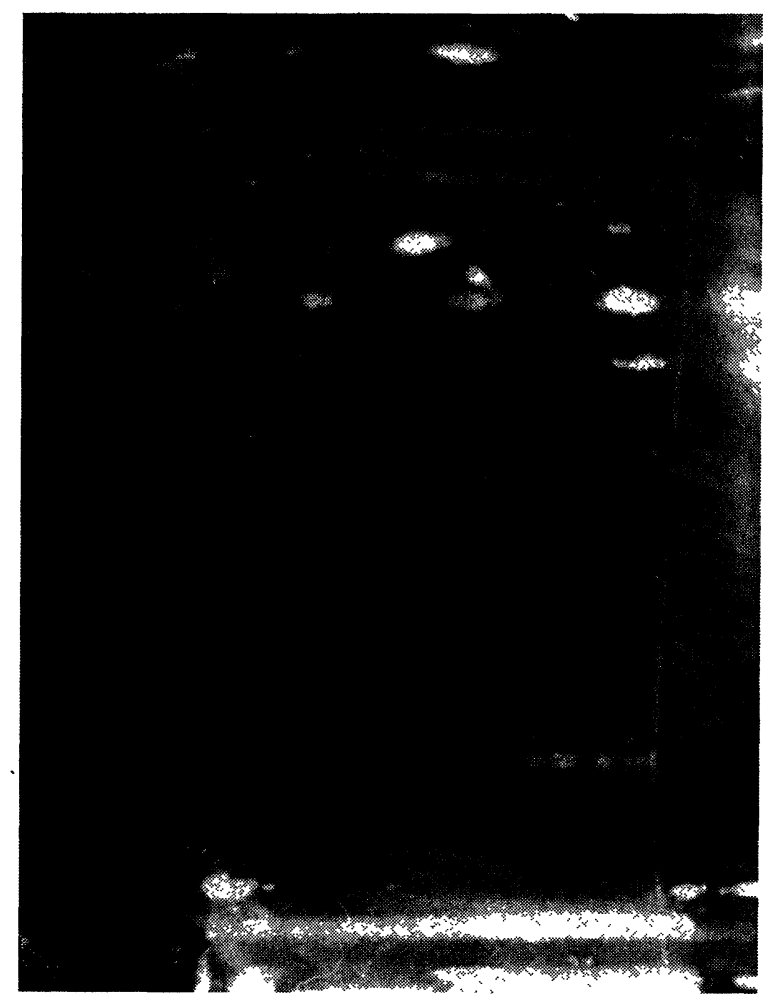

b)

Figs. $8 a$ and $b$. - Discharge tracks formed on stack insulators of the $5 \mathrm{MV}$ machine. 


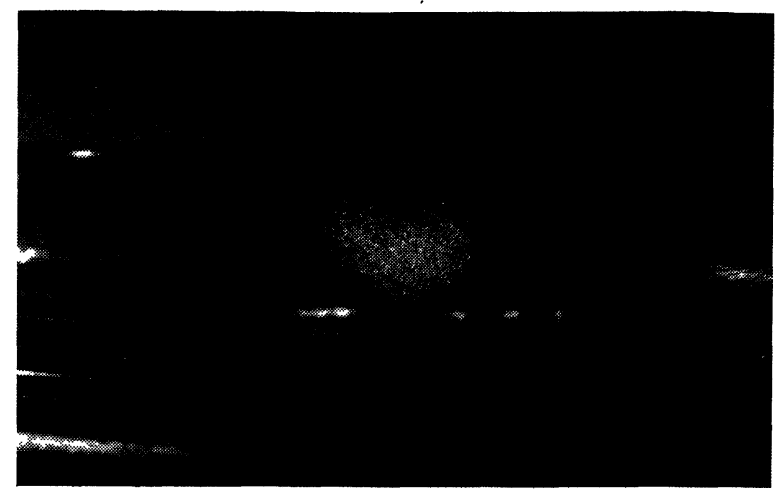

a)

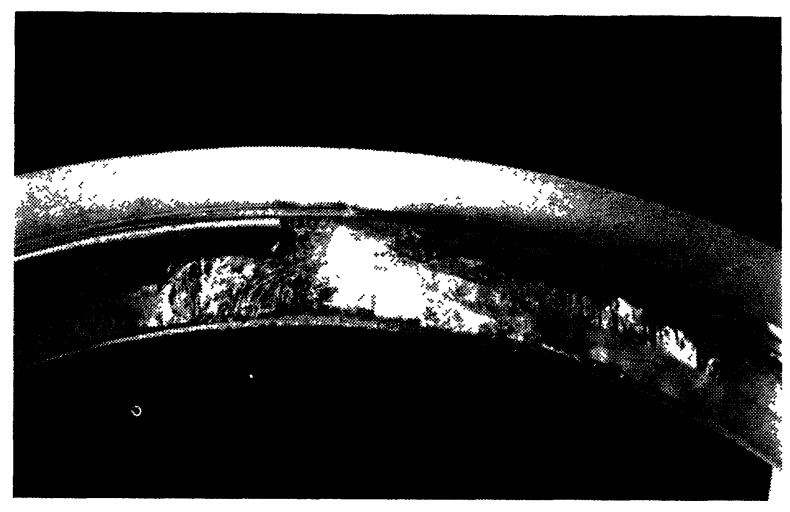

b)

FIGS. $9 a$ and $b$. - Discharge tracks formed on tube insulators of the $5 \mathrm{MV}$ machine.
In figures 6 and 7 the construction of the stack insulators and the tube elements [5] are shown.

5. Experiences. - Stack insulators and acceleration tubes have been operating nearly 10000 hours with good results.

From among the 180 stack insulators built in failed ones have been observed in three cases. The discharge tracks formed are quite of unusual shapes. Two of them are shown in figures $8 \mathrm{a}$ and $8 \mathrm{~b}$. No attempt has been made to explain the mechanism resulting in these tracks. The first track is definitely of volume character. In the second case the concentrical circles were formed on the inner surface of the hollow cylinder shape insulator.

A general browning of the glass appeared in the acceleration tube with decreasing intensity along the tube seen from the ion source. This effect was found to be of surface character [6] by a simple visual inspection of a broken acceleration tube ring. An increasing number of shallow erosion spots is appearing since about the eight thousandth working hour on the outer surface of the rings. The character of this erosion can clearly be seen in figure 9a. The figure $9 b$, was taken at the early period of running the generator. Here a breakdown shortening the inner extension of the ring can be seen. The appearance of this breakdown can be explained by too long distances between neighbouring sparking gaps outside the tube. In order to stop such type of breakdowns the number of sparking gaps has been increased.

\section{References}

[1] Koltay E., Szalay A., ATOMKI Közl. 16 (1974) 181.

[2] Koltay E., Mórik Gy., Somorjai E., ATOMKI Közl. 17 (1975) 131.

[3] Kiss A., Koltay E., Papp I., Szalay A., ATOMKI Közl. 18 (1976) 1.

[4] Kiss I., Koltay E., Bornemisza-Pauspertl P., Revue Phys. Appl. 12 (1977).

[5] Koltay E., Kiss A., Proceedings of the Int. Conf. on Technology of Electrostatic Accelerators, Daresbury 1973. DNPL/NSF/R5, 200.
[6] Electrostatic Generator Group Progress Report, Rutherford High Energy Laboratory. NIRL/R/23. 1962.

[7] Coker E. G., Filon L.N.G., A Treatise on Photo-Elasticity. (The University Press, Cambridge), 1931.

[8] GrimsEHL: Lehrbuch der Physik, 3. Band. (Herausgegeben von W. Schallreuter. Teubner Verlag. Leipzig), 1955, 138.

[9] Collins L. E., Howe F. A., Proceedings of the Int. Conf. on Technology of Electrostatic Accelerators, Daresbury 1973. DNPL/NSF/R5, 121.

[10] Dzmuran R., Report UJV 2262-A (1969). 